\title{
Conjunctival Pyogenic Granuloma - A Case Report
}

\author{
Pravin K. Tidake ${ }^{1}$, Sapan Jaiswal², Vishal Wagh ${ }^{3}$ \\ 1, 2, 3 Department of Ophthalmology, Jawaharlal Nehru Medical College, Datta Meghe Institute of Medical Sciences \\ (Deemed to Be University), Sawangi (Meghe), Wardha, Maharashtra, India.
}

\section{INTRODUCTION}

Pyogenic granuloma (PG) also known as lobular capillary haemangioma is a benign vascular tumour that is seen on the mucous membranes and in skin sometimes. It can be found intravascularly or subcutaneously. It mostly arises spontaneously and grows rapidly. ${ }^{1}$ Pyogenic granuloma may appear small or large, smooth or rough \& lobulated, or as reddish exophytic vascular nodules that can grow rapidly. Sometimes large lesions become lobulated which resemble a mushroom or pediculated tumour. PGs have a tendency to bleed profusely. Bleeding is the most common symptom of presentation. Pyogenic granuloma is an overgrowth of tiny blood vessels in large numbers.

\section{PRESENTATION OF CASE}

A 10-year-old male boy was brought by parents to ophthalmology clinic with chief complaints of swelling over right upper eyelid for 2 weeks and bleeding discharge since 2 months. The swelling had increased rapidly in size over the past 15 days causing irritation to the eye. Patients had used local anti-inflammatory eye drops and steroids, but symptoms were not relieved.

- Parents gave history of frequent eyelid rubbing by the patient,

- Patient did not have history of any trauma,

- No history of similar presentation in past,

- No history of chalazion.

\section{On Ophthalmic Examination}

In right eye, vision was 6 / 6; swelling was present on upper eyelid. Margins of upper eyelid were clear. The lobulated mass (pedunculated) was seen on upper tarsal conjunctiva of size $1 \mathrm{~cm} \mathrm{X} 0.5 \mathrm{~cm} \mathrm{X} 0.3 \mathrm{~cm}$ in size. The mass was cystic with blood collection in it. Cornea was bright. Iris had normal colour and pattern. The pupil was of normal size reacting to light. No changes in lens seen, left eye was normal.
Corresponding Author:

Dr. Vishal Wagh,

New Khetan Nagar,

Kaulkhed Road,

Akola - 444004,

Maharashtra, India.

E-mail: vishal10090@gmail.com

DOI: $10.14260 /$ jemds/2021/23

How to Cite This Article:

Tidake PK, Jaiswal S, Wagh V. Conjunctival pyogenic granuloma - a case report. J Evolution Med Dent Sci 2021;10(02):111113, DOI: $10.14260 / \mathrm{jemds} / 2021 / 23$

Submission 11-09-2020,

Peer Review 14-11-2020,

Acceptance 20-11-2020,

Published 11-01-2021.

Copyright (c) 2021 Pravin K. Tidake et al. This is an open access article distributed under Creative Commons Attribution License [Attribution 4.0 International (CC BY 4.0)] 


\section{CLINICAL DIAGNOSIS}

As the growth was single, red, pedunculated papule and it was present on mucosal surface i.e., conjunctiva, the size of the growth increased rapidly over a period of 15 days, so clinical diagnosis of pyogenic granuloma was made.

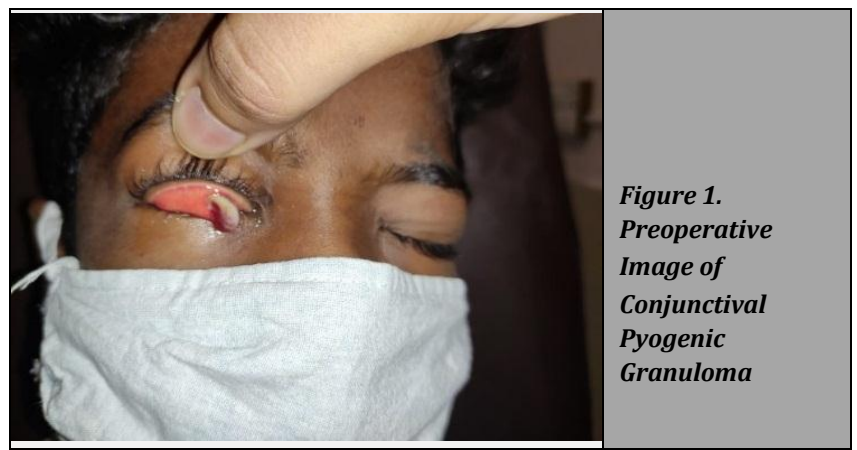

\section{DIFFERENTIAL DIAGNOSIS}

Acquired sessile haemangioma, Kaposi's sarcoma, cavernous haemangioma and glomangioma.

\section{PATHOLOGICAL DISCUSSION}

The haematoxylin and eosin (H\&E) stained section studied shows discontinuous stratified squamous epithelial lining along with fibrous septate formation and numerous vascular spaces in underlying stroma. These finding were suggestive of pyogenic granuloma.

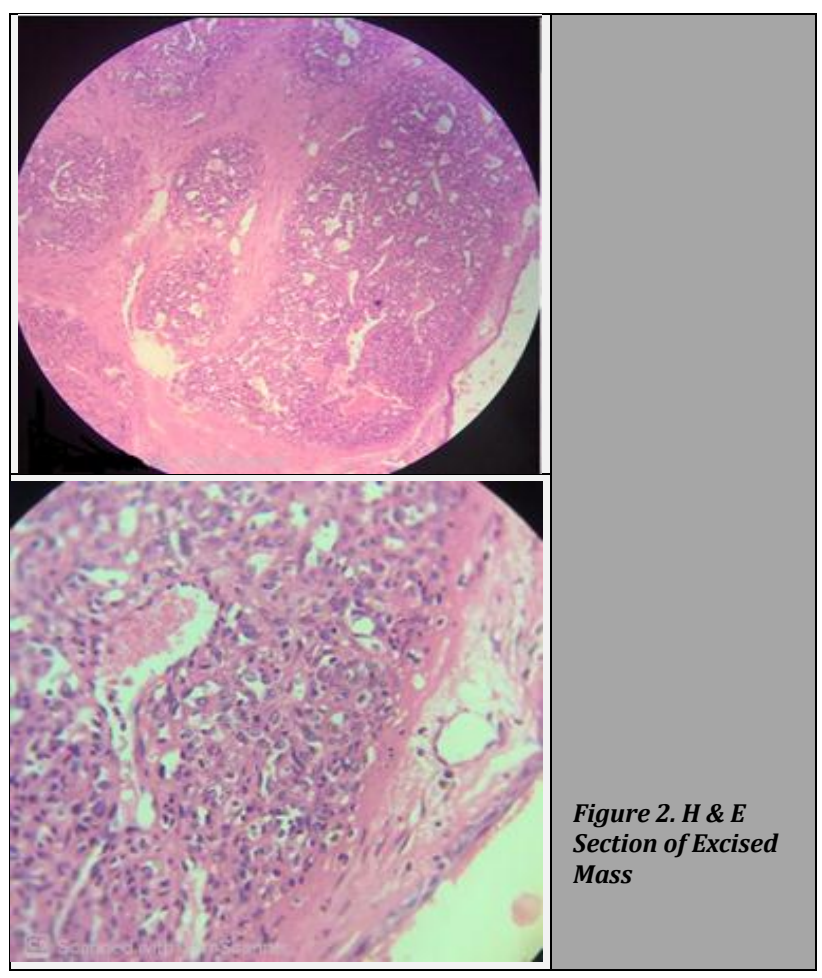

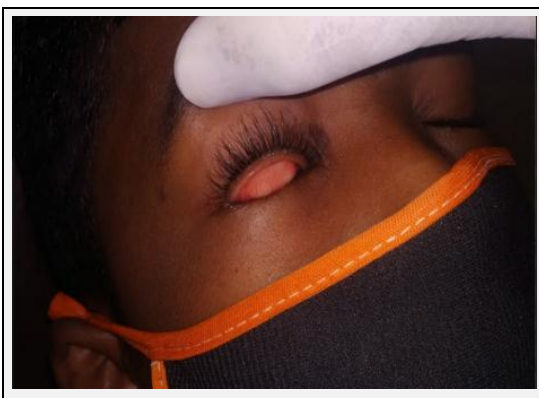

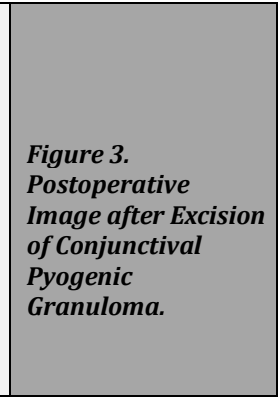

\section{DISCUSSION OF MANAGEMENT}

Since pyogenic granulomas do not regress on their own, they may bleed, ulcerate, or be cosmetically disfiguring, they may necessitate treatment on these grounds. Partial excision or curettage may lead to recurrence; hence, complete primary excision is preferred. ${ }^{2}$ In any surgical procedures, maintaining structural integrity remains a challenge. ${ }^{3-5}$ Post-operative follow-up evaluation is also very important. ${ }^{6-7}$

In our patient, we have done complete surgical resection, and the sample is sent for histopathology, which also suggested conjunctival pyogenic granuloma.

\section{DISCUSSION}

Pyogenic granuloma, also known as granuloma pyogenicum or lobulated capillary haemangioma, refers to a common, acquired, benign, vascular tumour that arises in skin and mucous membrane. ${ }^{8,9}$ The term pyogenic granuloma is a misnomer.

The aetiology of pyogenic granuloma is not known properly. Moreover, it is said to be due to imbalance of proangiogenic and anti-angiogenic factors, which results in rapid proliferation in capillary of neovascular, friable, and lobulated character. ${ }^{10}$ In one review, the incidence peaked in the second decade of life, and the lesion, are more commonly seen in males but the mucosal pyogenic granuloma is more common in females. ${ }^{11}$

The lesion generally seen as a single, red, pedunculated papule that is very friable. Less commonly, it may present as a sessile plaque. It shows rapid growth, and a surface often undergoes ulceration. It is often seen on cutaneous or mucosal surfaces. Among the mucous surfaces most common is oral cavity. Rarely, it may occur at other sites like within the gastrointestinal tract, and conjunctiva.

\section{FINAL DIAGNOSIS}

Conjunctival pyogenic granuloma in right eye.

\section{CONCLUSIONS}

Though pyogenic granuloma is relatively a common condition, it has to be differentiated from other lesions with similar 
clinical presentation, with appropriate treatment modalities it yields excellent results and should not be missed.

Financial or other competing interests: None.

Disclosure forms provided by the authors are available with the full text of this article at jemds.com.

\section{REFERENCES}

[1] Giblin AV, Clover AJP, Athanassopoulos A, et al. Pyogenic granuloma - the quest for optimum treatment: audit of treatment of 408 cases. J Plast Reconstr Aesthet Surg 2007;60(9):1030-5.

[2] Ahmed SAO, Ahmad AA, Musawa YA, et al. A case report of pyogenic granuloma of the upper eyelid. Ann Int Med Den Res 2017;3(5):DE13-5.

[3] Pareek A, Khandekar A, Acharya S, et al. Correlation between nephropathy and ophthalmic complications in cases of sickle cell anemia: an entangled association. Indian Journal of Medical Specialities 2019;10(2):72-5.

[4] Madhumita P, Daigavane S, Kalode V. Visual outcome after cataract surgery in rural hospital of Wardha district: a prospective study. Journal of Clinical and Diagnostic Research 2020;14(2):NC04-6.

[5] Daigavane S, Patkar P. To compare the changes in the corneal endothelium post phacoemulsification surgery with balanced salt solution vs. viscoelastic device. Journal of Clinical and Diagnostic Research 2019;13(12):1-4.

[6] Patkar P, Sune P. Evaluation of tear film functions preoperatively and postoperatively in cases with pterygium: a case control study. Journal of Clinical and Diagnostic Research 2020;14(1):NC10-3.

[7] Mukherji R, Sune P. Contrast sensitivity and visual acuity before and after ND:YAG capsulotomy in patients with posterior capsular opacification: a prospective study. Journal of Clinical and Diagnostic Research 2020;14(3):58.

[8] Wollina U, Langner D, França K, et al. Pyogenic granuloma - a common benign vascular tumor with variable clinical presentation: new findings and treatment options. Open Access Maced J Med Sci 2017;5(4):423-6.

[9] Mills SE, Cooper PH, Fechner RE. Lobular capillary hemangioma: the underlying lesion of pyogenic granuloma. A study of 73 cases from the oral and nasal mucous membranes. Am J Surg Pathol 1980;4(5):470-9.

[10] Andrikopoulou M, Chatzistamou I, Gkilas H, et al. Assessment of angiogenic markers and female sex hormone receptors in pregnancy tumor of the gingiva. J Oral Maxillofac Surg 2013;71(8):1376-81.

[11] Harris MN, Desai R, Chuang TY, et al. Lobular capillary hemangiomas: an epidemiologic report, with emphasis on cutaneous lesions. J Am Acad Dermatol 2000;42(6):10126. 